\title{
Constructing a psychological coping profile in the call centre environment: Wellness-related dispositions in relation to resiliency-related behavioural capacities
}

\author{
Author: \\ Nisha Harry ${ }^{1}$ \\ Affiliation: \\ ${ }^{1}$ Department of Industrial \\ Psychology, University of \\ South Africa, South Africa \\ Correspondence to: \\ Nisha Harry \\ Email: \\ harryn@unisa.ac.za \\ Postal address: \\ PO Box 392, Department of \\ Industrial Psychology, UNISA \\ Pretoria 0003, South Africa \\ Dates: \\ Received: 18 Jan. 2015 \\ Accepted: 28 April 2015 \\ Published: 21 Aug. 2015 \\ How to cite this article: \\ Harry, N. (2015). Constructing \\ a psychological coping \\ profile in the call centre \\ environment: Wellness- \\ related dispositions in \\ relation to resiliency-related \\ behavioural capacities. \\ SA Journal of Industrial \\ Psychology/SA Tydskrif vir \\ Bedryfsielkunde, 41(1), Art. \\ \#1265, 11 pages. http:// \\ dx.doi.org/10.4102/sajip. \\ v41i1.1265

\section{Copyright:} \\ (C) 2015. The Authors. \\ Licensee: AOSIS \\ OpenJournals. This work is \\ licensed under the Creative \\ Commons Attribution \\ License.
}

Read online:

Scan this $Q R$ code with your smart phone or mobile device to read online.
Orientation: The context of this research is the coping and wellness of call centre agents in a characteristically high-stress work environment.

Research purpose: The purpose of the study was to construct a psychological coping profile by investigating the overall relationship between individuals' wellness-related dispositional attributes and their resiliency-related behavioural capacities.

Motivation of the study: It is important that coping in the call centre environment be understood in light of the complexity of the challenges that call centre agents experience in terms of their wellbeing.

Research design, approach and method: A quantitative cross-sectional survey approach was followed, using a non-probability purposive sample $(N=409)$ comprising predominantly early career, permanently employed black females in call centres in Africa.

Main findings: A canonical correlation analysis indicated a significant overall relationship between the wellness-related constructs (sense of coherence, emotional intelligence and burnout) and the resiliency-related constructs (career adaptability and hardiness). Structural equation modelling indicated that managing own emotions and cynicism contributed significantly to explaining the participants' resiliency-related behavioural capacities (hardicommitment and hardi-control).

Practical/managerial implications: Enhancing call centre agents' emotional intelligence and lowering cynicism will increase resiliency-related capacities, such as sense of control and commitment, and will significantly increase the resiliency and capacity of call centre agents to cope with pressure, which can lead to positive work attitudes.

Contribution/value-add: The findings may provide valuable pointers for the design of wellness intervention practices and could potentially add to the body of knowledge concerned with employee wellness in call centres.

\section{Introduction}

The level of coping in the call centre environment is an increasing cause for concern, with negative terms such as 'electronic sweatshops' and 'factories of the future' ascribed to such environments. In addition, call centres are experiencing the effects of the high-stress levels experienced by call centre employees in the form of increased absenteeism, high staff turnover and low commitment coupled with a lack of attachment to the organisation (Latif, 2010). Accordingly, enhancing the wellness of call centre agents and helping them to develop the behavioural capacities they require to cope at work could lead them to a way of life that is oriented toward optimal health and wellbeing through the integration of the body, mind and spirit, consequently enabling these individuals to live more complete lives (Sieberhagen, Pienaar \& Els, 2011).

According to Banks and Roodt (2011), call centres have experienced tremendous growth in developing countries, including countries in Africa. However, absenteeism, high attrition rates, constant monitoring, the monotonous nature of the work, surveillance and regulation of negative emotions during customer interactions are some of the challenges experienced in these working environments (Banks \& Roodt, 2011; Borgogni, Consiglio, Alessandri \& Schaufeli, 2012). In addition, these challenges are compounded by the uncertainty in career-related transitions (Savickas \& Porfeli, 2012). It is therefore vital to conduct research into the psychological coping profile of call centre agents, as the complexities of call centre work make this type of work extremely stressful (Choi, Cheong \& Feinberg, 2012). 


\section{Research purpose and objectives}

This study focused on sense of coherence (SOC) (Antonovsky, 1991), emotional intelligence (Salovey \& Mayer, 1990), and burnout (De Lange, Dikkers \& Demerouti, 2010) as a composite set of wellness-related attributes, in relation to career adaptability (Savickas \& Porfeli, 2012) and hardiness (Kobasa, Maddi \& Kahn, 1982) as a composite set of resiliency-related behavioural capacities. More specifically, the aim of the study was to explore whether the wellnessrelated constructs explained a significant percentage of variance in the resiliency-related constructs. A significant overall relationship between these composite sets of variables may potentially constitute a psychological coping profile for the call centre agent. This research study focused on the positive aspects and the strengths of human behaviour by understanding holistically the strengths of coping patterns and adaptive abilities and the growth potential of individuals with the aim of compiling a coping profile for call centre agents (Diener et al., 2010).

The constructs of SOC and burnout in the call centre environment have been extensively researched (Harry, 2011). However, prior to this study, the notions of emotional intelligence, career adaptability and hardiness had not yet been researched in the context of a coping profile for call centre agents. In addition, research conducted in the call centre environment has focused primarily on ways of preventing and treating undesirable states of health (Consiglio, Borgogni, Allesandri \& Schaufeli, 2013).

\section{The potential value-add of the study}

It is hoped that this research study will contribute to existing wellness and positive psychology literature by investigating the relationship between wellness-related dispositional attributes and resiliency-related behavioural capacities in the call centre environment.

\section{Literature review}

\section{Coping behaviour in a call centre}

Call centres are characterised as a work environment in which the call centre agent sits all day, staring at a flickering computer screen and answering calls. This can take a major physical and emotional toll (Borgogni et al., 2012; Consiglio et al., 2013) and inevitably creates physical, psychological and behavioural deviations amongst employees as they have to sit continuously for approximately 8 hours. The repetitive nature of the service interactions increases stress and heightens an awareness amongst call centre agents to obtain psychosocial resources, which connect the internal (psychological) and external (social support) worlds of the call centre agent in order to facilitate coping (Borgogni et al., 2012; Harry \& Coetzee, 2013). These resources, which influence appraisal and coping responses, are likely to be found in interactionally intense settings such as call centre work (Harry \& Coetzee, 2013). The coping strategies found in these working environments include withdrawing from the work situation through absenteeism. This absence culture has been associated with employees' socially supportive efforts to cope with work demands (Borgogni et al., 2012; Consiglio et al., 2013).

It has been suggested that in order to cope with work demands certain internal resources such as wellness-related dispositional attributes (SOC, emotional intelligence and burnout) and resiliency-related behavioural capacities (career adaptability and hardiness) may assist individuals to cope better with high job demands than would otherwise have been the case. For the purposes of this research study, coping is viewed as the constantly changing cognitive and behavioural efforts that are made to manage specific internal demands which are appraised as taxing or exceeding the resources of the person concerned (Lazarus \& Folkman, 1984).

\section{Wellness-related behavioural capacities: Sense of coherence, emotional intelligence, burnout and coping}

The set of constructs which is regarded as wellness-related behavioural capacities for this study includes SOC, emotional intelligence and burnout. The first two constructs - SOC and emotional intelligence - have a positive effect on individuals' psychological wellbeing whilst burnout has a negative influence. Demanding conditions often lead to increased burnout.

SOC may be viewed in terms of the salutogenic theory, which relates to the ability to use resources to help resolve stress in a health-promoting manner (Antonovsky, 1984). SOC can be strengthened by cumulative life experiences; such experiences are referred to as generalised resistance resources (GRRs) and are characterised by 'participation in shaping the outcome' (Sairenchi et al., 2011). Three such experiences are manageability, comprehensibility and meaningfulness manageability is the feeling that one possesses sufficient resources to deal with stress; comprehensibility is the feeling that one has the capacity to recognise stress as understandable; and meaningfulness is the feeling that there is meaning to life (Cilliers, 2011; Sairenchi et al., 2011). SOC may be understood as a psychosocial resource which influences psychological and physiological responses to a particular stressor and is essential for successful coping, thereby ensuring maintenance of health (Harry \& Coetzee, 2013).

The theoretical foundations of emotional intelligence are based on four abilities, which include perceiving emotions, facilitating (using) emotions, understanding emotions and managing emotions (Salovey \& Mayer, 1990; Shaemi, Allameh \& Bajgerani, 2011). Emotional processes are crucial in daily functioning and tend to have an interactive effect on one another (Shaemi et al., 2011). Emotional information may assist individuals to understand their reactions to different stressors and this may in turn adaptively guide the coping process (Salovey \& Mayer, 1990). Emotional intelligence is often 
associated with higher levels of affective problem-solving, enabling individuals to adopt a multitude of problemsolving perspectives (Shaemi et al., 2011). Having increased emotional intelligence affords individuals more resources in allowing them to use the most adaptive problem-solving coping strategy for that particular situation (Shaemi et al., 2011; Yu-Chi, 2011). In addition, individuals who demonstrate high emotional intelligence seem to be more adept at stress management and decision-making and have faster mood recovery after disturbing and stressful experiences (Mayer, Salovey \& Caruso, 2008).

Burnout is an important variable not only because it is an indicator of poor employee wellbeing, but also because it is related to employees' attitude, health and behaviour (Maslach, 1982). Direct or passive coping styles may play an important role in burnout. Schaufeli (2004) defines burnout as the development of dysfunctional attitudes at work characterised by three components: exhaustion, cynicism and lack of professional efficacy. Exhaustion refers to feelings of being overextended and a perceived depletion of one's emotional and physical resources. Cynicism refers to negative, callous or excessively detached responses to various aspects of the job. Lack of professional efficacy represents feelings of incompetence and a lack of achievement and productivity at work (Lee \& Akhtar, 2011; Lee \& Choi, 2010). The high rate of burnout in a variety of professions, including call centres, has been associated with withdrawal coping strategies, such as getting away from people (De Lange et al., 2010). This can be regarded as a passive, avoidance coping style when dealing with emotional distress, and such strategies include ignoring the situation (De Lange et al., 2010; Harry \& Coetzee, 2013; Jordan, Blumenshine, Bertolone \& Heinrich, 2010; Lee \& Choi, 2010). If individuals can cope with stress by displaying positive behaviours it is regarded as a direct and active coping style. Low burnout levels have been associated with problem-focused coping behaviour aimed at modifying the stressor, as well as rational and task-oriented strategies (De Lange et al., 2010; Jordan et al., 2010).

In this study, SOC, emotional intelligence and burnout are viewed as wellness-related dispositional attributes. SOC motivates peoples to acquire coping mechanisms in response to demanding and challenging (stressful) situations (Harry \& Coetzee, 2013; Rothmann, Jackson \& Kruger, 2003; Sairenchi et al., 2011). Individuals who possess emotional skills and a sense of coherence are more likely to perform well in the workplace and to demonstrate positive behaviours (Rothmann et al., 2003). SOC and emotional intelligence have strong links with psychological wellbeing. Research has indicated that burnout is often associated with the high risk profiles of call centre agents and results when an employee is incapable of performing as a result of the fact that they are drained of energy (Harry, 2011). Research by Reissner et al. (2010) suggests that coping strategies mediate burnout in that they comprise stabilising cognitive and behavioural efforts to maintain psychosocial adaptation in times of stress.
Emotional intelligence has been found to lower burnout development by increasing the emotional coping resources and social skills that can benefit individuals in terms of health and wellness (Görgens-Ekermans \& Herbert, 2013). SOC is related to a lower rate of stress and can act as a buffer to burnout (Rothmann et al., 2003; Sairenchi et al., 2011).

In view of the constant changes that take place in the business environment, organisations need to maintain success by focusing on human strengths and the resources that support performance and health, as employees' wellbeing plays a vital role in the success of any organisation (Diener et al., 2010).

\section{Resiliency-related behavioural capacities: Career adaptability, hardiness and coping}

The present study focused on career adaptability and hardiness as important resiliency-related capacities that underpin coping behaviour. The resiliency-related behavioural capacities relate to the adaptive resources (i.e. the ability to cope in stressful and uncertain contexts). Career adaptability encompasses the attitudes, competencies and behaviours that individuals use in order to fit themselves into the careers that suit them (Ferreira, 2012a). Hardiness is viewed as a resiliencyrelated behavioural capacity in which individuals possess a constellation of personality characteristics that function as resistance resources in encounters with stressful life events (Kobasa et al., 1982, p. 169).

Career adaptability is conceptualised as self-regulatory strategies in terms of which individuals, using the developmental dimensions of self and environmental exploration, career planning and decision-making, look at the opportunities that are available and make viable choices (Savickas \& Porfeli, 2012). Adaptability takes into account the coping responses of the behaviours that are necessary to handle career changes. In the call centre environment, career adaptability is the most important resource in terms of coping as it relates to the resiliency and career satisfaction of call centre agents (Coetzee \& Esterhuizen, 2010).

The hardiness trait consists of three attitudes, namely commitment, control and challenge. Commitment, in which individuals view potentially stressful situations as meaningful and interesting, sees stressors as changeable (control) and regards change as a normal feature of life (challenge) (Kobasa et al., 1982). Hardiness theorists propose that hardiness influences the relationship between stressors and strain primarily through its effect on the appraisal and coping processes (Maddi \& Kobasa, 1984). The coping and appraisal processes involve individuals appraising stressors in a way that minimises the level of threat perceived and limits the amounts of negative arousal experienced (Kobasa 1982).

A psychological coping profile would contribute to the way in which adults cope and adjust to challenges of a changing world of work and adapt proactively to changing career 
circumstances. The concept of adaptability also reflects the ability to handle new challenging career contexts constructively (Hirschi, 2012). Hardiness is viewed as a collection of characteristics that function as flexible resources. Accordingly, hardy people appraise stressful events differently and gravitate towards more active coping strategies. Hardiness serves as a resiliency resource when stressful situations are encountered (Latif, 2010). Resilience occurs when individuals perceive themselves to be resilient and able to cope with the difficulties and challenges they face in life (Hutchinson, Purcell \& Kinnie, 2000).

This research was interested in studying the wellness-related attributes as a composite set of predictors of a composite set of resiliency-related behavioural capacities. The purpose of this approach was to explore whether the overall relationship dynamics between the two sets of composite variables could potentially inform coping behaviour in the call centre.

In terms of this study, it was expected that the wellness-related dispositional attributes, which act as internal resources, would strengthen the psychosocial strengths and resiliency capacities, namely career adaptability and hardiness. Exploring the overall relationship between the wellnessrelated attributes (SOC, emotional intelligence and burnout) and the resiliency-related capacities (career adaptability and hardiness) could potentially provide valuable insights into the way these constructs contribute to the coping profile of the call centre agents.

The following research hypothesis was formulated:

Individuals' wellness-related capacities (SOC, emotional intelligence and burnout) significantly explain the variance in their resiliency-related behavioural capacities (career adaptability and hardiness).

\section{Research design Research approach}

A quantitative research approach was followed to achieve the research objective. This study took the form of a crosssectional research study and generated primary data from a non-probability purposive sample.

\section{Research method}

\section{Participants}

This study comprised a non-probability purposive sample of 409 permanently employed black call centre agents between the ages of 25 and 40 years, who were employed in three of the largest outsourced financial call centres in Africa. Women comprised $65.8 \%$ of the sample and men $34.2 \%$. An $82 \%$ response rate was obtained.

\section{Measuring instruments}

The measuring instruments for the wellness-related dispositions included the Orientation to Life Questionnaire
(OLQ-29), the Assessing Emotions Scale (AES) and the Maslach Burnout Inventory Scale (MBI).

To measure SOC, the Orientation to Life Questionnaire (OLQ-29), developed by Antonovsky (1987), was used. Items are scored on a seven-point ordinal rating scale ranging from 'very often' (1) to 'very seldom or never' (7) for five of the items and from 'no clear goals or purpose at all' (1) to 'very clear goals and purpose' (7) for the remaining items. The following dimensions are measured: comprehensibility (11 items; e.g. 'Does it happen that you have feelings inside you would rather not feel?), manageability (10 items; e.g. 'When something unpleasant happened in the past your tendency was: "To eat yourself up" about it versus to say "OK, that's that, I have to live with it", and so on') and meaningfulness (8 items; e.g. 'You anticipate that your personal life in the future will be: totally without meaning or purpose versus full of meaning and purpose'). A South African-based study conducted by Bezuidenhout and Cilliers (2010) reported an overall Cronbach's alpha of 0.90 for the OLQ. As regards this study, the following Cronbach's alpha (internal consistency reliability) values were obtained: comprehensibility (0.64), manageability (0.57), meaningfulness (0.71) and overall scale (0.78). The somewhat lower internal consistency reliability coefficients $(0.57$ and 0.64$)$ were considered in the interpretation of the data analysis. Although a Cronbach's alpha of 0.70 is preferred, in the social sciences a Cronbach's alpha of 0.60 is regarded as an acceptable level of internal consistency for broad research purposes (Hair, Black, Babin \& Anderson, 2010). The value of 0.57 was regarded as being close to 0.60 and therefore acceptable.

The study utilised the Assessing Emotions Scale (AES) developed by Schutte et al. (1998) to measure emotional intelligence. This scale is used to measure the following four emotional intelligence traits: perception of emotion (10 items; e.g. 'I am aware of my emotions as I experience them'), managing own emotions (9 items; e.g. 'I have control over my emotions'), managing others' emotions (8 items; e.g. 'I like to share my emotions with others') and utilisation of emotions (6items; e.g. 'When my mood changes, I see new possibilities'). It is a 33-item, self-report scale with a five-point Likert scale $(1=$ strongly disagree; $5=$ strongly agree). Validity studies on the AES have justified the various underlying constructs of the four subscales (Chapman \& Hayslip, 2006; Ciarrochi, Chan \& Caputi, 2009; Saklofske, Austin \& Minksi, 2003). In terms of reliability (internal consistency), Ciarrochi et al. (2009) reported Cronbach's alpha coefficients of 0.55 (moderate) to 0.78 (high). In this study, the following Cronbach's alpha (internal consistency reliability) values were obtained: perception of emotion (0.55), managing own emotions (0.73), managing others' emotions (0.72), utilising emotions (0.61) and overall scale (0.87). The somewhat lower internal consistency reliability coefficients (0.55 and 0.61) were considered in the interpretation of the data analysis.

The 16-item Maslach Burnout Inventory General Scale (MBI-GS), developed by Maslach, Jackson and Leiter (1996), is aimed at assessing participants' level of burnout. 
The MBI-GS includes items that measure emotional exhaustion (five items; e.g. 'Working all day is really a strain for $\mathrm{me}^{\prime}$ ), cynicism (five items; e.g. 'I doubt the significance of my work'), and professional efficacy (six items; e.g. 'I have accomplished many worthwhile things in this job'). Respondents are expected to rate their responses as $1=$ strongly disagree up to $6=$ strongly agree and $3=$ neither agree nor disagree. All items were scored on a six-point Likert-type frequency rating scale, ranging from 0 (never) to 6 (every day). The higher the number, the truer that item is for the respondent. South African-based studies (Rothmann \& Malan, 2003) have reported internal consistency reliabilities ranging between 0.70 and 0.89 . This study obtained the following Cronbach's alpha (internal consistency reliability) values: exhaustion (0.87), cynicism (0.77), professional efficacy (0.73) and overall scale (0.81).

The measuring instrument for the resiliency-related behavioural capacities included the Career Adapt-Abilities Scale (CAAS) and the Personal Views Survey II (PVS-II).

The original, research-based version of the Career AdaptAbilities Scale (CAAS), developed by Savickas (2010), was used to measure the participants' career adaptability. A fivepoint Likert-type scale ( $1=$ not strong; $5=$ strongest $)$ was used to measure a participant's responses to each of the 55 items. The dimension concern has 11 items and measures the individual's concern about his or her vocational future (e.g. 'Planning important things before I start'). The dimension control has 11 items and measures the individual's control in order to assist his or her preparation for a vocational future (e.g. 'Making decisions by myself'). The dimension curiosity has 11 items and measures the construct of curiosity by exploring possible selves and future scenarios (e.g. 'Exploring my surroundings'). The dimension cooperation has 11 items and measures the individual's cooperation displayed within his or her career (e.g. 'Becoming less selfcentred'). The dimension confidence, which has 11 items, measures the individual's confidence in pursuing his or her aspirations (e.g. 'Performing tasks efficiently'). A South African-based study conducted by Ferreira (2012b) reported internal consistency reliability values ranging between 0.88 and 0.90 . This study obtained the following Cronbach's alpha coefficient (internal consistency reliability) values: concern (0.84), control (0.81), curiosity (0.80), cooperation (0.83), confidence (0.87) and overall scale (0.95).

The Personal Views Survey II (PVS-II), which was developed by Maddi (1987), was used to measure the participants' hardiness. A four-point Likert-type scale was used to measure all of the 50 items ( $1=$ not at all true; $4=$ completely true) for the following three subscales: commitment-alienation (15 items; e.g. 'I often wake up eager to take up my life where I left it off the day before' and 'Most of my life is wasted doing things that don't mean anything'), control-powerlessness (17 items; e.g. 'Planning ahead may help avoid most future problems' and 'No matter how hard I try, my efforts will accomplish nothing') and challenge-threat (18 items; e.g. 'I enjoy being with people who are unpredictable' and 'I want to be sure someone will take care of me when I get old'). As regards internal consistency reliability, Maddi (1987) reported the following Cronbach's alpha coefficients: 0.70 to 0.75 for commitment; 0.61 to 0.84 for control; 0.60 to 0.71 for challenge and 0.80 to 0.88 for total hardiness. This study found the following Cronbach's alpha (internal consistency reliability) values: control-powerlessness (0.79), commitmentalienation (0.83), challenge-threat (0.65) and overall scale (0.90). The somewhat lower internal consistency reliability coefficients (0.65) were considered in the interpretation of the data analysis.

\section{Research procedure and ethical considerations}

Ethical clearance was obtained from the research institution and permission to conduct the research study was obtained from the human resource manager of the call centres involved. All questionnaires chosen were regarded as fair, reliable and valid. All participants' information was treated with respect and confidentiality. The measuring instruments, as well as the process involved in gathering the data, followed a valid and reliable procedure. Ethical and employment equity issues were taken into consideration in this study.

\section{Statistical analysis}

Descriptive statistics (means, standard deviations and Cronbach's alphas), bivariate correlations and multivariate statistics were obtained in order to realise the objective of the study. Canonical correlation analysis (SAS, 2008) was used to study the multivariate relationships between the wellnessrelated constructs (SOC, emotional intelligence and burnout) and the resiliency-related constructs (career adaptability and hardiness). As a powerful technique for evaluating overall relationships between multiple data sets, canonical correlation analysis has several advantages for a researcher, as the technique limits the probability of committing Type I errors (Hair et al., 2010). Canonical correlation places the fewest restrictions on the types of multivariate data in which it operates, is of a higher quality and may be presented in a more interpretable manner than, for example, multiple regression analysis or exploratory factor analysis (Hair et al., 2010). Wilk's multivariate test criterion and the redundancy index were used to assess the practical effect size of the full model.

Structural equation modelling (Amos 18) (Arbuckle, 2009) was further performed to assess the overall structural model fit between the two composite sets of variables (wellnessrelated and resiliency-related constructs). The following goodness-of-fit statistics were relevant for assessing overall data fit: the chi-square test, the root mean square error of approximations (RMSEA) of 0.08 or lower, and the standardised root mean square residual (SRMR) of 0.05 or lower. The following relative goodness-of-fit indices were used: the comparative fit index (CFI) of 0.90 or higher, and the Tucker-Lewis index (TLI) of 0.90 or higher. Because several models were compared in order to obtain the best fit model, the Akaike information criterion (AIC) and Bayes information criterion (BIC) values were also considered, with the lowest values indicating a better model fit. 


\section{Results Descriptive statistics and correlations}

Table 1 presents an overview of the means, standard deviations, internal consistency reliabilities and correlations between the variables of the wellness-related dispositional attributes. The table shows significant correlations between the sense of coherence and burnout variables $(r \geq 0.12 \leq r \leq 0.89$; small to large practical effect; $p \leq 0.05$ ), with negative correlations $(r \leq-0.10 \leq r \leq-0.39$ small to large effect) for the burnout (MBI) variables.

Table 2 presents an overview of the means, standard deviations, internal consistency reliabilities and correlations between the variables of the resiliency-related behavioural capacities. The table shows significant correlations between the career adaptability and hardiness variables $(r \geq 0.13 \geq$ $r \leq 0.69$; small to large practical effect; $p \leq 0.05$ ) and negative correlations $(r \geq-0.12 \geq r \leq-0.15$; small to large practical effect; $p \leq 0.05$ ) for the PVS-II challenge-threat variable.

\section{Canonical correlation analyses}

Table $3 \mathrm{a}$ and Table $3 \mathrm{~b}$ present the results of the standardised canonical analyses for the first canonical function.

Table $3 \mathrm{a}$ and Table $3 \mathrm{~b}$ show that the canonical correlation model displayed eight canonical functions (dimensions) of which the canonical correlations of the first five functions only were statistically significant. The full model $r^{2}$ type effect size (yielded by $1-0 . \lambda$ : $1-0.22$ ) was 0.78 (large practical effect), indicating that the full model explained a substantial portion - approximately $78 \%$ - of the variance shared between the two variable sets. The overall canonical correlation in Table $4 \mathrm{a}$ and Table $4 \mathrm{~b}$ show that the relationship between the two canonical variate constructs was fairly strong $(R c=0.75)$. The canonical variables of the first function accounted for $56 \%$ of the data variability. However, only the results of the first canonical function were used for testing the research hypothesis because the second function explained only an additional $31 \%$ of the variance shared between the two variable sets the data variability, the third function only $10 \%$, the fourth function only $8 \%$ and the fifth function also only $8 \%$.

The redundancy index results summarised in Table 4a and Table $4 \mathrm{~b}$ show that, although the wellness-related canonical construct variables accounted for $56 \%\left(R c^{2}=0.56\right.$; large practical effect) of the proportion of variance in the resiliencyrelated canonical construct variables, the wellness-related construct variables were able to predict only $18 \%$ (moderate effect) of the variance in the individual original resiliencyrelated canonical construct variables.

The wellness-related canonical construct variables contributed significantly in explaining the variance in the eight original resiliency-related constructs (career adaptability and hardiness) variables, namely career concern (35\%); career control (35\%); career curiosity $(23 \%)$; career

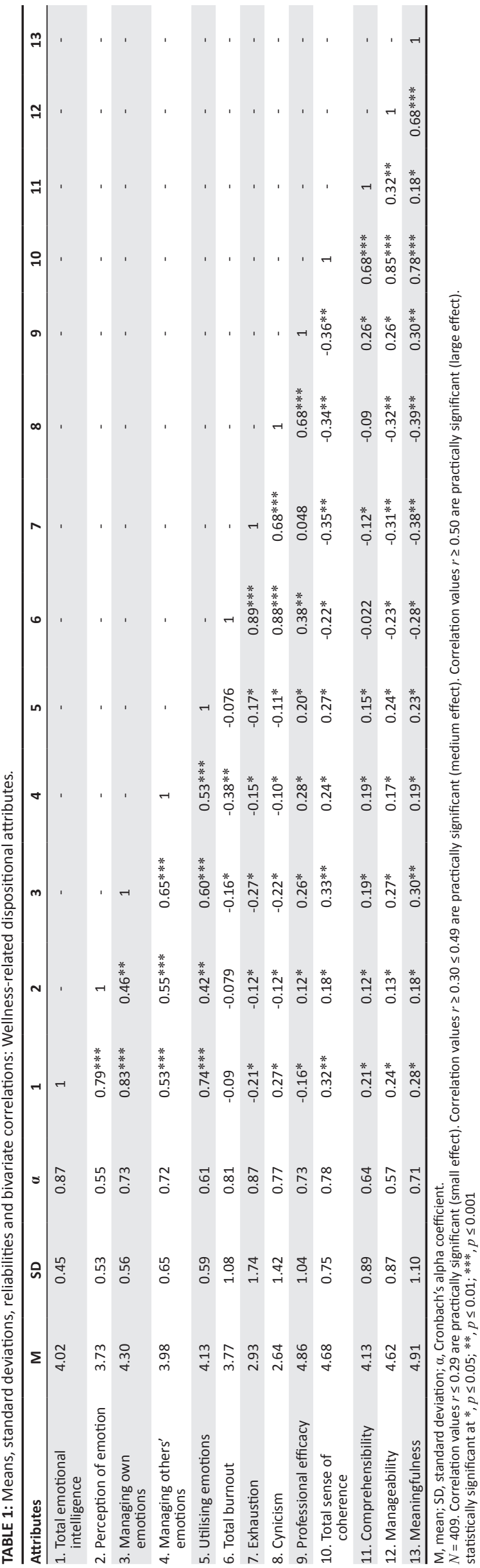


TABLE 2: Means, standard deviations, reliabilities and bivariate correlations: Resiliency-related behavioural capacities.

\begin{tabular}{|c|c|c|c|c|c|c|c|c|c|c|c|}
\hline Attributes & M & SD & $\alpha$ & 1 & 2 & 3 & 4 & 5 & 6 & 7 & 8 \\
\hline 1. Career concern (CAAS) & 4.19 & 0.57 & 0.84 & 1 & - & - & - & - & - & - & - \\
\hline 2. Career control (CAAS) & 4.26 & 0.52 & 0.81 & $0.68 * * *$ & 1 & - & - & - & - & - & - \\
\hline 3. Career curiosity (CAAS) & 4.00 & 0.65 & 0.80 & $0.61 * * *$ & $0.68 * * *$ & 1 & - & - & - & - & - \\
\hline 4. Career cooperation (CAAS) & 3.77 & 0.68 & 0.83 & $0.58 * * *$ & $0.58 * * *$ & $0.63 * * *$ & 1 & - & - & - & - \\
\hline 5. Career confidence (CAAS) & 4.16 & 0.60 & 0.87 & $0.60 * * *$ & $0.68 * * *$ & $0.69 * * *$ & $0.62 * * *$ & 1 & - & - & - \\
\hline 6. Commitment-alienation (PVS-II) & 3.00 & 0.55 & 0.83 & $0.14 *$ & $0.18^{*}$ & 0.09 & 0.06 & $0.20 *$ & 1 & - & - \\
\hline 8. Challenge-threat (PVS-II) & 2.36 & 0.37 & 0.65 & -0.06 & -0.09 & $0.13 *$ & $-0.12 *$ & $-0.15^{*}$ & $0.59 * * *$ & $0.56 * * *$ & 1 \\
\hline
\end{tabular}

M, mean; SD, standard deviation; $\alpha$, Cronbach's alpha coefficient; CAAS, Career Adapt-Abilities Scale; PVS-II, Personal Views Survey II.

$N=409$. Correlation values $r \leq 0.29$ are practically significant (small effect). Correlation values $r \geq 0.30 \leq 0.49$ are practically significant (medium effect). Correlation values $r \geq 0.50$ are practically significant (large effect)

Statistically significant at $*, p \leq 0.05 ; * *, p \leq 0.01 ; * * *, p \leq 0.001$

TABLE 3a: Canonical correlation analysis - Overall model fit statistics.

\begin{tabular}{|c|c|c|c|c|c|}
\hline \multirow[t]{2}{*}{ Canonical function } & \multicolumn{5}{|c|}{ Measures of overall model fit for canonical correlation analysis } \\
\hline & $\begin{array}{l}\text { Overall canonical correlation } \\
(\mathrm{Rc})\end{array}$ & $\begin{array}{l}\text { Overall squared canonical } \\
\text { correlation }\left(\mathrm{Rc}^{2}\right)\end{array}$ & Eigenvalue & F statistics & Probability $(p)$ \\
\hline 1 & 0.75 & 0.56 & 1.2806 & 8.97 & $<0.0001 * * *$ \\
\hline 2 & 0.56 & 0.31 & 0.4511 & 4.95 & $<0.0001 * * *$ \\
\hline 3 & 0.32 & 0.10 & 0.1158 & 2.96 & $<0.0001 * * *$ \\
\hline 4 & 0.29 & 0.08 & 0.0926 & 2.70 & $<0.0001 * * *$ \\
\hline 5 & 0.27 & 0.08 & 0.0844 & 2.32 & $<0.0001 * * *$ \\
\hline 6 & 0.16 & 0.03 & 0.0257 & 1.25 & 0.24 \\
\hline 7 & 0.11 & 0.01 & 0.0127 & 0.89 & 0.50 \\
\hline 8 & 0.04 & 0.001 & 0.0013 & 0.25 & 0.78 \\
\hline
\end{tabular}

Statistically significant at $*, p \leq 0.05 ; * *, p \leq 0.01 ; * * *, p \leq 0.001$.

TABLE 3b: Canonical correlation analysis - Overall model fit statistics.

\begin{tabular}{lccc}
\hline Statistic & Value & Approximate $\boldsymbol{F}$ statistic & Probability $(p)$ \\
\hline Wilks' Lambda & 0.22 & 8.97 & $<0.0001^{* * *}$ \\
Pillai's Trace & 1.18 & 7.31 & $<0.0001^{* * *}$ \\
Hotelling-Lawley Trace & 2.06 & 10.68 & $<0.0001^{* * *}$ \\
Roy's Greatest Root & 1.28 & 54.21 & $<0.0001^{* * *}$ \\
\hline
\end{tabular}

$N=409$.

Statistically significant at $*, p \leq 0.05 ; * *, p \leq 0.01 ; * * *, p \leq 0.001$

cooperation $(19 \%)$; career confidence $(39 \%)$; commitmentalienation (65\%); control-powerlessness $(68 \%)$ and challengethreat $(30 \%)$. Managing own emotions $(R c=0.53)$ and meaningfulness $(R c=0.51)$ exhibited the highest correlation with the canonical resiliency-related canonical construct variate. Managing own emotions $(R c=0.71)$ and cynicism $(R c=-0.73)$ were the strongest predictors of the wellnessrelated canonical construct variate. Control-powerlessness $(R c=0.68)$ and commitment-alienation $(R c=0.65)$ exhibited the highest correlation with the canonical wellness-related canonical construct variate and were also the strongest predictors of the resiliency-related canonical construct variate (control-powerlessness: $R_{c}=0.91$; commitmentalienation: $R c=0.87)$.

\section{Structural equation modelling}

Using the results of the canonical correlation analysis as the baseline measurement model, structural equation modelling was performed to assess the overall model fit between the two composite sets of data (the wellness-related canonical construct and its variables in relation to the resiliency-related canonical construct and its variables). Three alternative models were tested; the third model produced the best fit.
Modification of the models in order to improve fit was based on what made theoretical sense.

Table 5 summarises the fit statistics of the three models that were tested. The first model included all the wellnessrelated construct variables (OLQ, AES and MBI variables) and also all the resiliency-related construct variables (CAAS and PVS-II variables). However, the model did not produce a good fit with the data: chi-square (CMIN) 337.32 (49 degrees of freedom $[d f]$ ); CMIN $/ d f=6.884 ; p=0.000$; Bentler-Bonett normed fit index $(\mathrm{NFI})=0.86$; relative fit index $(\mathrm{RFI})=0.81 ; \mathrm{TLI}=0.83 ; \mathrm{CFI}=0.88, \mathrm{RMSEA}=0.12$ and $\mathrm{SRMR}=0.11 ; \mathrm{AIC}=395.39 ; \mathrm{BIC}=510.34$.

The second model included only managing own emotions, meaningfulness and cynicism (wellness-related constructs) and career confidence, commitment-alienation and controlpowerlessness (resiliency-related constructs). However, the model data fit did not improve: CMIN = 157.18 (13 df); $\mathrm{CMIN} / d f=12.09 ; p=0.000 ; \mathrm{NFI}=0.87 ; \mathrm{RFI}=0.79 ; \mathrm{TLI}=$ $0.80 ; \mathrm{CFI}=0.88, \mathrm{RMSEA}=0.16, \mathrm{SRMR}=0.098$ and $\Delta \mathrm{CMIN}=$ 180.14; $\mathrm{AIC}=246.67 ; \mathrm{BIC}=187.18$.

As seen in Figure 1, after the modification one has to estimate 9 parameters and 10 sample moments (10-9) $=1$, which generated 1 degree of freedom. This model included only managing own emotions and cynicism (wellnessrelated construct) and commitment-alienation and controlpowerlessness (resiliency-related construct), thus producing a good fit with the data: CMIN = 1.22 (1 df); CMIN/ $d f=1.22 ; p=0.000 ; \mathrm{NFI}=0.998 ; \mathrm{RFI}=0.99 ; \mathrm{TLI}=0.998$; $\mathrm{CFI}=1.00$, $\mathrm{RMSEA}=0.02, \mathrm{SRMR}=0.006$; and $\Delta \mathrm{CMIN}=155.96$; 
TABLE 4a: Standardised canonical correlation analysis results for the first canonical function variate.

\begin{tabular}{|c|c|c|c|c|}
\hline Variate/variables & Canonical coefficient (weight) & $\begin{array}{c}\text { Structure coefficient (canonical } \\
\text { loading) }(R c)\end{array}$ & Canonical cross-loadings $(R c)$ & $\begin{array}{c}\text { Squared multiple correlation } \\
\left(R c^{2}\right)\end{array}$ \\
\hline Perception of emotion (AES) & -0.0001 & 0.33 & 0.24 & 0.06 \\
\hline Managing own emotions (AES) & 0.50 & 0.71 & 0.53 & 0.28 \\
\hline Managing others' emotions (AES) & 0.47 & 0.39 & 0.29 & 0.08 \\
\hline Comprehension (OLQ) & -0.05 & 0.23 & 0.16 & 0.03 \\
\hline Manageability (OLQ) & 0.09 & 0.58 & 0.44 & 0.19 \\
\hline Meaningfulness (OLQ) & 0.19 & 0.68 & 0.51 & 0.26 \\
\hline Exhaustion (MBI) & -0.14 & -0.62 & -0.47 & 0.22 \\
\hline Professional efficacy (MBI) & 0.27 & 0.47 & 0.36 & 0.13 \\
\hline Cynicism (MBI) & -0.43 & -0.73 & -0.55 & 0.30 \\
\hline
\end{tabular}

$N=409 ;$ AES, Assessing Emotions Scale; OLQ, Orientation to Life Questionnaire; MBI, Maslach Burnout Inventory; CAAS, Career Adapt-Abilities Scale; PVS-II, Personal Views Survey II; $d f$, degree of freedom; * $p \leq 0.05 ; * *, p \leq 0.01 ; * * *, p \leq 0.001$.

Overall model fit measures (function 1 ):

Overall $R c^{2}=0.56$

$F(p)=8.97(p<0.0001) ; d f=72 ; 2282.50$

Wilk's lambda $(\lambda)=0.22$

Redundancy index proportion $=0.18$

Percentage of overall variance of variables explained by their own canonical variables: 0.31 ; Resiliency-related behavioural capacities canonical variate (dependent variables); Wellness-related dispositional attributes canonical variate (independent variables).

TABLE 4b: Standardised canonical correlation analysis results for the first canonical function variate.

\begin{tabular}{|c|c|c|c|c|}
\hline Variate/variables & Canonical coefficient (weight) & $\begin{array}{l}\text { Structure coefficient (canonical } \\
\text { loading) }(R c)\end{array}$ & Canonical cross-loadings ( $R c)$ & $\begin{array}{c}\text { Squared multiple correlation } \\
\left(R c^{2}\right)\end{array}$ \\
\hline Concern (CAAS) & 0.22 & 0.46 & 0.35 & 0.11 \\
\hline Control (CAAS) & 0.09 & 0.46 & 0.35 & 0.11 \\
\hline Cooperation (CAAS) & -0.05 & 0.25 & 0.19 & 0.03 \\
\hline Confidence (CAAS) & 0.23 & 0.51 & 0.39 & 0.14 \\
\hline Commitment-Alienation (PVS-II) & 0.42 & 0.87 & 0.65 & 0.43 \\
\hline Challenge-Threat (PVS-II) & -0.14 & 0.40 & 0.30 & 0.09 \\
\hline
\end{tabular}

$N=409 ;$ AES, Assessing Emotions Scale; OLQ, Orientation to Life Questionnaire; MBI, Maslach Burnout Inventory; CAAS, Career Adapt-Abilities Scale; PVS-II, Personal Views Survey II; $d f$, degree of freedom; $* p \leq 0.05 ; * *, p \leq 0.01 ; * * *, p \leq 0.001$.

Overall model fit measures (function 1 ):

Overall $R c^{2}=0.56$

$F(p)=8.97(p<0.0001) ; d f=72 ; 2282.50$

Wilk's lambda $(\lambda)=0.22$

Redundancy index proportion $=0.18$

Percentage of overall variance of variables explained by their own canonical variables: 0.31 ; Resiliency-related behavioural capacities canonical variate (dependent variables).

TABLE 5: Structural equation modelling results: Fit statistics $(N=409)$.

\begin{tabular}{lccccccccccccc}
\hline Model & CMIN $\left(\chi^{2}\right)$ & $d f$ & CMIN/ $\boldsymbol{f}$ & $\boldsymbol{P}$ & NFI & RFI & TLI & CFI & $\Delta$ CMIN & RMSEA & SRMR & AIC & BIC \\
\hline 1 & 337.32 & 49 & 6.884 & 0.00 & 0.86 & 0.81 & 0.83 & 0.88 & 185.12 & 0.12 & 0.11 & 395.39 & 510.34 \\
2 & 157.18 & 13 & 12.09 & 0.00 & 0.87 & 0.79 & 0.80 & 0.88 & 180.14 & 0.16 & 0.098 & 246.67 & 187.18 \\
3 & 1.22 & 1 & 1.22 & 0.00 & 0.998 & 0.99 & 0.998 & 1.00 & 155.96 & 0.02 & 0.006 & 19.22 & 54.92 \\
\hline
\end{tabular}

CMIN $\left(\chi^{2}\right)$, chi-square; $d f$, degrees of freedom; $p$, significance level; NFI, Bentler-Bonett normed fit index; RFI, relative fit index; TLI, non-normed fit index; CFI, comparative fit index; RMSEA, rootmean-square error of approximation; SRMR, standardised root-mean-square residual; AIC, Akaike information criterion; BIC, Bayes information criterion.

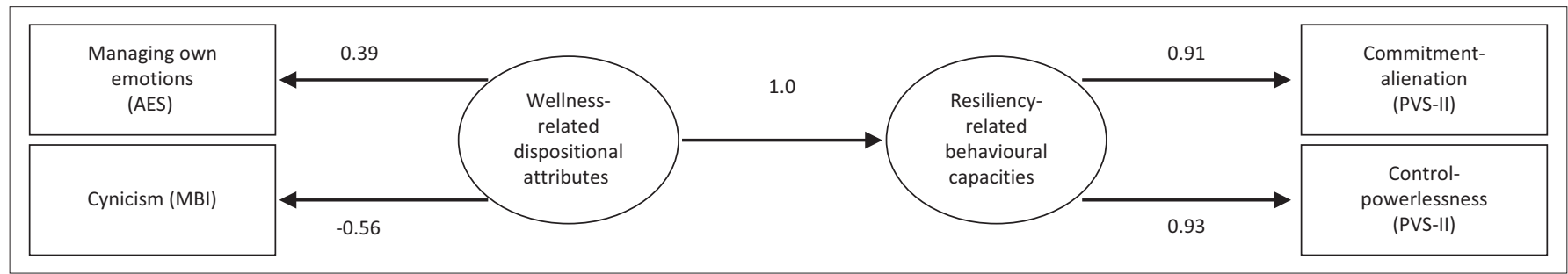

Note: All standardised path coefficient estimates ***, $p \leq 0.001$. AES, Assessing Emotions Scale; MBI, Maslach Burnout Inventory; PVS-II, Personal Views Survey II.

FIGURE 1: Best fit structural model (model 3) linking the significant wellness-related dispositional attributes construct variables with the resiliency-related behavioural capacities construct variables.

$\mathrm{AIC}=19.22 ; \mathrm{BIC}=54.92$. The best fit model is in line with the observations made in terms of the canonical correlation analyses about the best predictors of each construct.

Figure 1 specifies the standardised path coefficients between the wellness-related dispositional attributes construct and its variables and the standardised path coefficients between the resiliency-related behavioural capacities and its variables as per the best fit model. The standardised path coefficient estimates between the wellness-related dispositional attributes construct and the resiliency-related behavioural capacities construct are also specified. Similar to the results 
observed in the canonical correlation analysis, managing own emotions $(\beta=0.39)$ and cynicism $(\beta=-0.56)$ were the strongest predictors of the wellness-related dispositional attributes construct, with cynicism accounting for the most and negatively in explaining the variance in the wellnessrelated construct.

Commitment-alienation $(~(\beta=0.91)$ and control-powerlessness ( $(=0.93)$ were the strongest predictors of the resiliency-related behavioural capacities construct, with control-powerlessness contributing the most and positively in explaining the variance in the resiliency-related construct. Overall, the wellness-related dispositional attributes construct positively predicted the resiliency-related behavioural capacities construct $(\beta=1.0)$. The squared multiple correlations showed that the model explained $100 \%$ of the variance in the overall resiliency-related construct, $86 \%$ of the variance in controlpowerlessness and $83 \%$ of the variance in commitmentalienation (large practical effect).

\section{Discussion}

The purpose of the study was to construct a psychological coping profile by investigating the overall relationship between the wellness-related dispositional attributes and the resiliency-related-behavioural capacities. More specifically, the study explored whether the wellness-related construct variables explained a significant percentage of variance in the resiliency-related construct variables. Overall, the research results suggest that the wellness-related dispositional attributes (managing own emotions and cynicism) contributed significantly to explaining the participants' resiliency-related behavioural capacities (hardi-commitment and hardi-control). These attributes and capacities seem to be important to consider in the psychological coping profile of the call centre agent.

As part of their psychological coping, the participants appeared to be aware of their own emotions and felt confident in managing them, which appears to have strengthened their sense of hardi-control and hardi-commitment, and thus their resiliency in coping. Research conducted by Yu-Chi (2011) revealed that individuals who have high emotional intelligence are able to use and regulate their own emotions; they are generally aware of their emotions and they maintain a positive mental state - a situation that leads to overall wellness. Managing own emotions is both proactive and problem-focused. Research conducted by Pillay, Viviers and Mayer (2013) suggests that individuals who possess high emotional intelligence have the ability to perceive and adapt their emotions effectively by accurately perceiving emotions and, thus, promoting intellectual growth.

Hardi-control enables individuals to be active, even in uncertain situations, and this in turn allows individuals to be involved rather than detached. The control aspect relates to the participants striving to exert an influence on external outcomes, which acts as a resiliency to stress (Kobasa, 1982). The results of the present study are in agreement with the findings of Ferreira (2012a), which suggest that individuals who demonstrate commitment and control are effective in coping with stress. It would appear that employees who have the ability to manage their own emotions also possess a sense of emotional self-efficacy and that they exert control over their personal emotions by using a positive mood to enable them to persevere in spite of obstacles, which, according to the results of the present study, contribute to a higher sense of commitment and control (Latif, 2010).

The results further suggest that the participants' cynicism or the depersonalisation aspect of burnout may decrease the perception of control and commitment in stressful times, which may potentially lead to lower levels of resiliency as expressed by a higher sense of alienation and powerlessness (De Beer, Pienaar \& Rothmann, 2013).

High levels of cynicism may lower resiliency capacities. Research has shown that call centres may likely be prone to individuals developing a negative and callous attitude towards call centre work, which reduces the tendency to involve oneself in life (Kotzé \& Lamb, 2012). According to Kotzé and Lamb (2012), this results in individuals reflecting an indifference towards work, which can lower a participant's hardi-control and hardi-comittment and is likely to render them powerless in the belief that they cannot influence life's events through their own efforts. Cynicism in a call centre environment can be addressed by taking into consideration individuals' hardiness coping strategies, as hardy individuals rely more on adaptive (transformational) coping strategies such as problem-focused coping and support seeking (Maddi \& Kobasa, 1984). These individuals would then be less likely to use passive coping strategies such as emotionfocused coping and distancing (Maddi \& Kobasa, 1984). It is the combination of commitment, control and challenge that constitutes existential courage and motivation.

\section{Limitations}

As the study was confined to call centre agents only, it is not possible to generalise the findings to other occupational contexts. Moreover, the sample size was not necessarily large enough to establish whether there is a definite relationship between the variables of sense of coherence, emotional intelligence, burnout, career adaptability and hardiness, as only three call centres were approached and participation was voluntary.

The study was cross-sectional in nature and therefore it was not possible to ascertain the causal directions of relations. Owing to the cross-sectional nature and self-reporting approach followed, the associations between the variables could also have been influenced by common method variance.

However, in terms of this research study, self-reports were probably the most accurate means of assessment because they involve internal psychological processes. It is recommended that the study be replicated in other occupational contexts 
with a broader representation of various age, race and socioeconomic groups before more extensive conclusions can be drawn.

\section{Conclusions}

The value of the findings may potentially relate to the identification of key wellness-related attributes and resiliency-related capacities that provide insight into the coping behaviour of call centre agents.

It is recommended that organisations increase hardiness amongst their employees by equipping them with the resources they need to manage their workload (Coetzee \& Harry, 2014). Highly committed individuals apply emotional resources in order to cope with excessive workloads. A sense of hardi-control is viewed as an important resource to assist individuals in this regard, whilst hardi-commitment reflects individuals who are committed to themselves and their work and who experience a sense of control over their lives (Alarcon, Eschleman \& Bowling, 2009; Ferreira, 2012b).

It is essential that organisations understand the complex process involved in coping with the challenges and demands of career development in the 21st century, especially in a call centre environment, and that they assist individuals to recognise their personal strengths and the positive psychosocial resources necessary for adjusting to the changing contextual circumstances affecting their working lives (Coetzee \& Harry, 2014). This study identified the ability to manage one's own emotions and low cynicism as important coping attributes in strengthening the resiliency (hardi-commitment and hardi-control) of the call centre agent.

More specifically, organisational wellness practices should focus on developing both the wellness-related dispositional attributes and the resiliency-related behavioural capacities, which are highlighted in the findings of this study as the personal resources and resiliency resources that increase health and wellbeing. As pointed out by Cilliers (2011) and Sieberhagen et al. (2011), wellness practices may increase the psychological wellbeing and motivation of individuals, thus it is essential that positive organisations encourage their employees to be proactive in their personal development. In addition, organisations should focus on both the strengths and the needs of their employees.

This research contributes to wellness literature by exploring the relationship dynamics between multiple wellness-related and resiliency-related constructs in the coping of call centre agents.

\section{Acknowledgements Competing interests}

The author declares that she does not have financial or personal relationship(s) which may have inappropriately influenced her in writing this article.

\section{References}

Alarcon, G., Eschleman, K.J., \& Bowling, N. (2009). Relationships between personality variable and burnout: A meta-anlaysis. Journal of Work and Stress, 23(3), 244-263. http://dx.doi.org/10.1080/02678370903282600

Antonovsky, A. (1984). A call for a new question - salutogenesis - and a proposed answer - sense of coherence. Journal of Preventative Psychiatry, 2(1), 1-11.

Antonovsky, A. (1987). Unravelling the mystery of health: How people manage stress and stay well. San Francisco, CA: Jossey-Bass.

Antonovsky, A. (1991). Personality and stress: Individual differences in the stress process. Chichester: Wiley.

Arbuckle, J.L. (2009). Amos 18 user's guide. Crawfordville, FL: Amos Development Corporation.

Banks, D., \& Roodt, G. (2011). The efficiency and quality dilemma: What drives South African call centre management performance indicators? South African Journal of Human Resource Management, 9(1), Art. \#331, 17 pages.

Bezuidenhout, A., \& Cilliers, F.V.N. (2010). Burnout, work engagement and sense of coherence in female academics in higher-education institutions in South Africa. South African Journal of Industrial Psychology, 36(1), Art. \#872, 10 pages.

Borgogni, L., Consiglio, C., Allesandri, G., \& Schaufeli, W.B. (2012). 'Don't throw the baby out with the bathwater': Interpersonal strain at work and burnout. European Journal of Work \& Organisational Psychology, 21(6), 875-898. http://dx.doi.org/10.1080/13 59432X.2011.598653

Chapman, B.P., \& Hayslip, B. (2006). Emotional intelligence in young and middle adulthood: Cross-sectional analysis of latent structure and means. Psychology and Aging, 21, 411-418. http://dx.doi.org/10.1037/0882-7974.21.2.411

Choi, S., Cheong, K.J., \& Feinberg, R.A. (2012). Moderating effects of supervisor support, monetary rewards, and career paths on the relationship between job support, monetary rewards, and career paths on the relationship between job
burnout and turnover intentions in the context of call centers. Managing Service Quality, 22(5), 492-516. http://dx.doi.org/10.1108/09604521211281396

Ciarrochi, J., Chan, A., \& Caputi, P. (2009). A critical evaluation of the emotional intelligence construct. Personality and Individual Differences, 28(3), 539-561. http://dx.doi.org/10.1108/09604521211281396

Cilliers, F. (2011). Positive psychology leadership coaching experiences in a financial organisation. South African Journal of Industrial Psychology, 37(1), Art. \#933, 14 pages.

Coetzee, M., \& Esterhuizen, K. (2010). Psychological career resources and coping resources of the young unemployed African graduates: An exploratory study. South African Journal of Industrial Psychology, 36(1), 1-9. http://dx.doi. org/10.4102/sajip.v36i1.868

Coetzee, M., \& Harry, N. (2014). Emotional intelligence as a predicator employees' career adaptability. Journal of Vocational Behaviour, 84, 90-97.

Consiglio, C., Borgogni, L., Allesandri, G., \& Schaufeli, W.B. (2013). Does self-efficacy matter for burnout and sickness absenteeism? The mediating role of demands and resources at the individual and team levels. Work \& Stress, 27(1), 22-42. http://dx.doi.org/10.1080/02678373.2013.769325

De Beer, L.T., Pienaar, J., \& Rothmann Jr., S. (2013). Investigating the reversed causality of engagement and burnout in job demands-resources theory. South African Journal of Industrial Psychology, 39(1), Art. \#1055, 9 pages.

De Lange, A.H., Dikkers, J.S.E., \& Demerouti, E. (2010). A self-regulatory perspective on the effects of humour styles in relation to burnout and work engagement. Nottingham: European Academy of Occupational Health Psychology (EAOHP).

Diener, E., Wirtz, D., Tov, W., Kim-Prieto, C., Choi, D., Oishi, S., \& Biswas-Diener, R. (2010). New wellbeing measures: Short scales to assess flourishing and positive and negative feelings. Social Indicators Research, 9, 143-156. http://dx.doi org/10.1007/s11205-009-9493-y

Ferreira, N. (2012a). Constructing a psychological career profile for staff retention. Unpublished doctoral dissertation. University of South Africa, Pretoria, South Africa.

Ferreira, N. (2012b). Hardiness in relation to organisational commitment in the human resource management field. SA Journal of Human Resource Management, 10(2), Art. \#418, 10 pages.

Görgens-Ekermans, G., \& Herbert, M. (2013). Psychological capital: Internal and external validity of the Psychological Capital Questionnaire (PCQ-24) on a South African sample. SA Journal of Industrial Psychology, 39(2), Art. \#1131, 12 pages.

Hair, J., Black, W., Babin, B. \& Anderson, R. 2010. Multivariate data analysis. Upper Saddle River, NJ: Prentice Hall.

Harry, N. (2011). Sense of coherence, affective wellbeing and burnout in a call centre. Unpublished master's thesis, University of South Africa, Pretoria, South Africa.

Harry, N., \& Coetzee, M. (2013). Sense of coherence, career adaptability and burnout of early-career Black staff in the call centre environment. SA Journal of Industrial Psychology, 39(2), Art. \#1138, 10 pages.

Hirschi, A. (2012). The career resources model: An integrative framework for career counsellors. British Journal of Guidance \& Counselling, 140(4), 369-383. http:// dx.doi.org/10.1080/03069885.2012.700506

Hutchinson, S., Purcell, J., \& Kinnie, N. (2000). Evolving high commitment management and the experience of the RAC call centre. Human Resource Management Journal, 10(1), 63-78. http://dx.doi.org/10.1111/j.1748-8583.2000.tb00014.x

Jordan, J., Blumenshine, E., Bertolone, M., \& Heinrich, F. (2010). Burnout among intellectual disability staff. Washington: American Psychological Association (APA). 
Kobasa, S. (1982). The hardy personality: Toward a social psychology of stress and health. In G.S. Sanders \& J. Suls (Eds.), Social psychology of health and illness. health. In G.S. Sanders \& J. Suls (Eds.), Social psychology of health
Hillside, NJ: Erlbaum. http://dx.doi.org/10.1037/0022-3514.42.1.168

Kobasa, S.C., Maddi, S.R., \& Kahn, S. (1982). Hardiness and health: A perspective study. Journal of Personality and Social Psychology, 42(1), 168-177.

Kotzé, M., \& Lamb, S., (2012). The influence of personality traits and resilience on burnout among customer service representatives in a call centre. Journal of Social Sciences, 32(3), 295-309.

Latif, J. (2010). An investigation into the moderating effects of hardiness between performance monitoring and life satisfaction in a call centre environment. Unpublished master's thesis, University of Witwatersrand, Johannesburg, South Africa.

Lazarus, R., \& Folkman, S. (1984). Stress, appraisal, and coping. New York, NY: Springer.

Lee, J.S.Y., \& Akhtar, S. (2011). Effects of the workplace social context and job content on nurse burnout. Human Resource Management Journal, 50(2), 227-245. http:// dx.doi.org/10.1002/hrm.20421

Lee, S.M., \& Choi, B.Y. (2010). Individual and work-related factors influencing burnout of mental health professionals: A meta-analysis. Nottingham: European Academy of Occupational Health Psychology (EAOHP).

Maddi, S.R. (1987). Hardiness training at Illinois Bell Telephone. In J.P. Optz (Ed.) Health promotion evaluation (pp. 101-116). Stevens Point, WI: National Wellness Institute.

Maddi, S., \& Kobasa, S. (1984). The hardy executive: Health under stress. Chicago, IL: Dorsey Professional Books.

Maslach, C. (1982). Burnout: The cost of caring. Engelwood Cliffs, NJ: Prentice-Hall.

Maslach, C., Jackson S.E., \& Leiter, M.P. (1996). Maslach burnout inventory manual. (3rd edn.). Mountain View, CA: CPP.

Mayer, J.D., Salovey, P., \& Caruso, D.R. (2008). Emotional intelligence: New ability or eclectic traits? The American Psychologist, 63(6), 503-517. http://dx.doi. org/10.1037/0003-066X.63.6.503

Pillay, M., Viviers, R., \& Mayer, C. (2013). The relationship between emotional intelligence and leadership styles in the South African petrochemical industry. $S A$ Journal of Industrial Psychology, 39(1), Art. \#1109, 12 pages.

Reissner, V., Baune, B., Kokkevi, A., Schifano, F., Room, R., Palm, J., et al. (2010). Burnout, coping and job satisfaction in service staff treating opioid addicts: From Athens to Zurich. Stress \& Health: Journal of the International Society for the Investigation of Stress, 26(2), 149-159. http://dx.doi.org/10.1002/smi.1276
Rothmann, S., Jackson, L.T.B., \& Kruger, M.M. (2003). Burnout and job stress in a local government: The moderating effects of sense of coherence. South African Journal of Industrial Psychology, 29(4), 52-60. http://dx.doi.org/10.4102/sajip. Journal of

Rothmann, S., \& Malan, H. (2003). Sense of coherence, self-efficacy, locus of control and burnout of social workers. South African Journal of Industrial Psychology, 29(4), 43-51.

Sairenchi, T., Haruyama, Y., Ishikawa, Y., Wada, K., Kimura, K., \& Muto, T. (2011). Sense of coherence as a predictor of onset of depression among Japanese workers: A cohort study. BMC Public Health, 11(1), 205-209. http://dx.doi. org $/ 10.1186 / 1471-2458-11-205$

Saklofske, D.H., Austin, E.J., \& Minski, P.S. (2003). Factor structure and validity of a trait emotional intelligence measure. Personality and Individual Differences, 34(4), 707-721. http://dx.doi.org/10.1016/S0191-8869(02)00056-9

Salovey, P., \& Mayer, J.D. (1990). Emotional intelligence. Imagination, Cognition \& Personality, 9(3), 185-211. http://dx.doi.org/10.2190/DUGG-P24E-52WK-6CDG

SAS. (2008). SAS Version 9.2. Cary, NC: SAS Institute Inc.

Savickas, M. (2010). The Career Adapt-Abilities Scale. Personal documentation received from author at the 27th International Congress of Applied Psychology (ICAP), 11-16 July, Melbourne.

Savickas, M.L., \& Porfeli, E.J. (2012). The Career Adapt-Abilities Scale: Construction, reliability, and measurement equivalence across 13 countries. Journal of Vocational Behavior, 80, 661-673. http://dx.doi.org/10.1016/j.jvb.2012.01.011

Schaufeli, W.B. (2004, March). Burnout and engagement. Paper presented at the $2 \mathrm{nd}$ South African Work Wellness Conference, Potchefstroom, South Africa.

Schutte, N., Malouff, J., Hall, E., Haggerty, D., Cooper, J., Golden, D., \& Dornheim, L. (1998). Development and validation of a measure of emotional intelligence. Personality and Individual Differences, 25, 167-177. http://dx.doi.org/10.1016/ S0191-8869(98)00001-4

Shaemi, A., Allameh, S.M., \& Bajgerani, M.A. (2011). Impact of talent management strategies on employees' emotional intelligence in Isfahan Municipality (Iran) Interdisciplinary Journal of Contemporary Research in Business, 3(6), 229-241.

Sieberhagen, C., Pienaar, J., \& Els, C. (2011). Management of employee wellness in South Africa: Employer, service provider and union perspectives. SA Journal of Human Resource Management, 9(1), Art. \#305, 14 pages.

Yu-Chi, W.U. (2011). Job stress and job performance among employees in the Taiwanese finance sector: The role of emotional intelligence. Social Behavior \& Personality: An International Journal, 39(1), 21-31. 